06

\title{
Влияние функционализации на электропроводность и шумовые характеристики массивов многостенных углеродных нанотрубок
}

\author{
(C) В.А. Сергеев, ${ }^{1,2}$ Е.С. Климов, ${ }^{2}$ И.В. Фролов ${ }^{1, \text { Ф }}$ \\ ${ }^{1}$ Ульяновский фрилиал Института радиотехники и электроники им. В.А. Котельникова Российской академии наук, \\ 432071 Ульяновск, Россия \\ ${ }^{2}$ Ульяновский государственный технический университет, \\ 432027 Ульяновск, Россия \\ T e-mail: ilya-frolov88@mail.ru
}

Поступило в Редакцию 20 декабря 2017 г.

В окончательной редакции 11 марта 2019 г.

Принято к публикации 11 марта 2019 г.

Исследованы электрофизические и шумовые характеристики массивов многостенных углеродных нанотрубок (МУНТ), функционализированных различными способами. Показано, что по значению удельного сопротивления и его температурной зависимости массивы исходных МУНТ и МУНТ после отжига относятся к полупроводникам, а массивы из отожженных и функционализированных кислотами МУНТ проявляют металлические свойства. У всех образцов массивов МУНТ в диапазоне $0.2-20 \mathrm{kHz}$ наблюдался НЧ-шум вида $1 / f$, при этом простой температурный отжиг приводил к увеличению уровня шума в несколько раз, а отжиг с обработкой кислотами - к снижению уровня шума и изменению показателя степени в его токовой зависимости. С увеличением плотности массивов исходных МУНТ распределение выбросов шума по амплитуде трансформируется из нормального в логарифмически-нормальное, а распределение по длительности - сжимается.

Ключевые слова: многостенные углеродные нанотрубки, массивы нанотрубок, функционализация, шумовые характеристики, электропроводность.

DOI: 10.21883/JTF.2019.08.47895.2608

\section{Введение}

Углеродные нанотрубки (УНТ) являются объектом многочисленных исследований благодаря своим уникальным физико-химическим свойствам и получают все большее применение во многих областях науки и техники, в том числе и в микроэлектронике [1]. Широкий спектр их применения основан на уникальных механических, электрических и теплофизических свойствах наноструктур, что проявляется при включении нанотрубок в матрицы различных материалов и приводит к появлению новых структурно-реологических и физико-химических свойств композитов.

Электрофизические свойства и особенности токопрохождения в массивах УНТ исследуются достаточно давно. В ряде работ [2,3] показано, что электрофизические свойства массивов одностенных и многостенных УНТ определяются степенью сжатия массива. Эти свойства зависят не только от степени сжатия (т.е. плотности образцов), но и от вида и режима функционализации УНТ [4-7].

Дополнительным источником информации о механизмах переноса носителей заряда в таких неоднородных средах является электрический шум. Наличие $1 / f$ шума в массивах УНТ отмечают многие исследователи $[8,9]$, но большинство из них ограничиваются анализом частотных и токовых зависимостей спектральной плотности мощности шума. Модели, описывающие шумовые свойства массивов УНТ, основываются на механизмах переноса носителей заряда в перколяционных средах с ловушками. При этом в литературе отсутствует информация о таких вероятностных характеристиках электрических шумов в массивах УНТ, как распределение выбросов шума по амплитуде и времени. Это и определило цели и задачи исследования.

\section{Технология получения и функционализации МУНТ}

Многостенные углеродные нанотрубки (МУНТ) получены на разработанной в Ульяновском государственном техническом университете экспериментальной лабораторной установке методом MOCVD в токе аргона с использованием прекурсоров толуола и ферроцена [10]. Фотография синтезированных исходных МУНТ, полученная на электронном микроскопе, приведена на рис. 1.

Отжиг МУНТ на воздухе проводили при $450^{\circ} \mathrm{C}$ в течение $40 \mathrm{~min}$, после чего материал обрабатывали соляной кислотой при $90^{\circ} \mathrm{C}$ в течение $20 \mathrm{~h}$.

Функционализацию смесью азотной и серной кислот проводили в круглодонной колбе объемом $500 \mathrm{ml}$, снабженной обратным холодильником, при температуре $90^{\circ} \mathrm{C}$ при постоянном перемешивании. В колбу помещали $4 \mathrm{~g}$ МУНТ и приливали $200 \mathrm{ml}$ смеси концентрированных серной и азотной кислот в объемном 


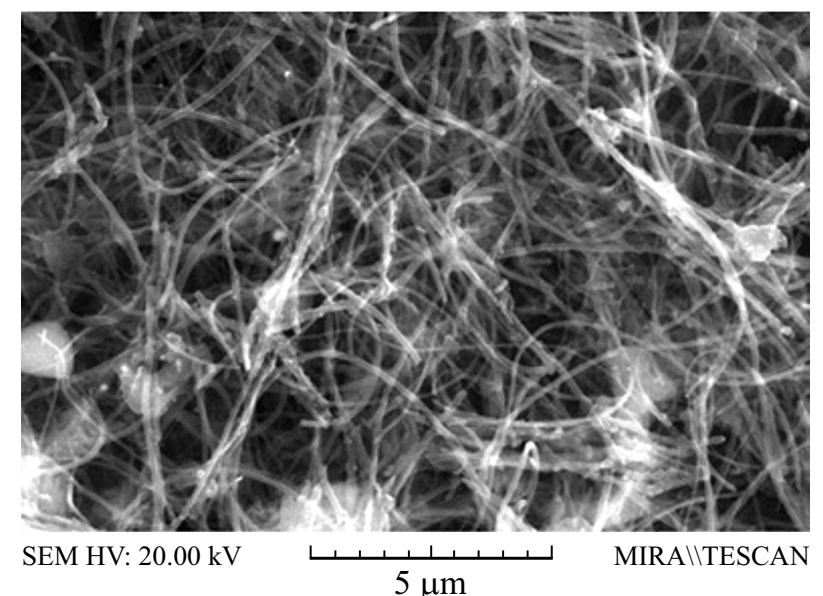

Рис. 1. Фотография синтезированных МУНТ, полученная на электронном микроскопе при увеличении $\times 800$.

соотношении $(3: 1)$. Слежение за процессом проводили потенциометрическим титрованием смеси на количество привитых на поверхности МУНТ карбоксильных групп. Оптимальное время функционализации составило $70 \mathrm{~min}$. Полученную суспензию фильтровали на стеклянном фильтре, многократно промывали дистиллированной водой до отсутствия реакции на сульфат-ионы в элюате. Отмытый порошок сушили в сушильном шкафу при $90-100^{\circ} \mathrm{C}$ в течение $8 \mathrm{~h}$. Подробно методики функционализации описаны в работе [4].

Исходные МУНТ обрабатывали в металлическом гомогенизаторе для получения мелкодисперсного продукта. Для приготовления образцов проводили ультразвуковую обработку (лабораторная установка погружного типа „ИЛ 100-6/4“, частота $22 \mathrm{kHz}$ ) в изопропиловом спирте с последующим высушиванием при $100^{\circ} \mathrm{C}$ в течение $6 \mathrm{~h}$.

\section{Методика измерения электрофизических характеристик массива МУНТ}

Для измерения электрофизических характеристик массивов МУНТ разработана контактная система, изображенная на рис. 2. Подобные конструкции контактных систем использовались и авторами $[3,5,6]$. Массив МУНТ помещается в кювету, выполненную из полой керамической трубки внутренним диаметром $d=1.6 \mathrm{~mm}$ и внешним диаметром $2.6 \mathrm{~mm}$. К кювете подведены два электрода: неподвижный и подвижный. Оба электрода имеют диаметр $d=1.6 \mathrm{~mm}$. В эксперименте использованы три типа электродов: медные, алюминиевые и медные, торцы которых покрыты припоем ПОС-61. Подвижный электрод соединен с микрометрическим винтом, что позволяло изменять высоту $h$ рабочего объема кюветы (рис. 2) в пределах $0-10 \mathrm{~mm}$ с шагом $25 \mu \mathrm{m}$. Кювета размещается внутри нихромового нагревателя,

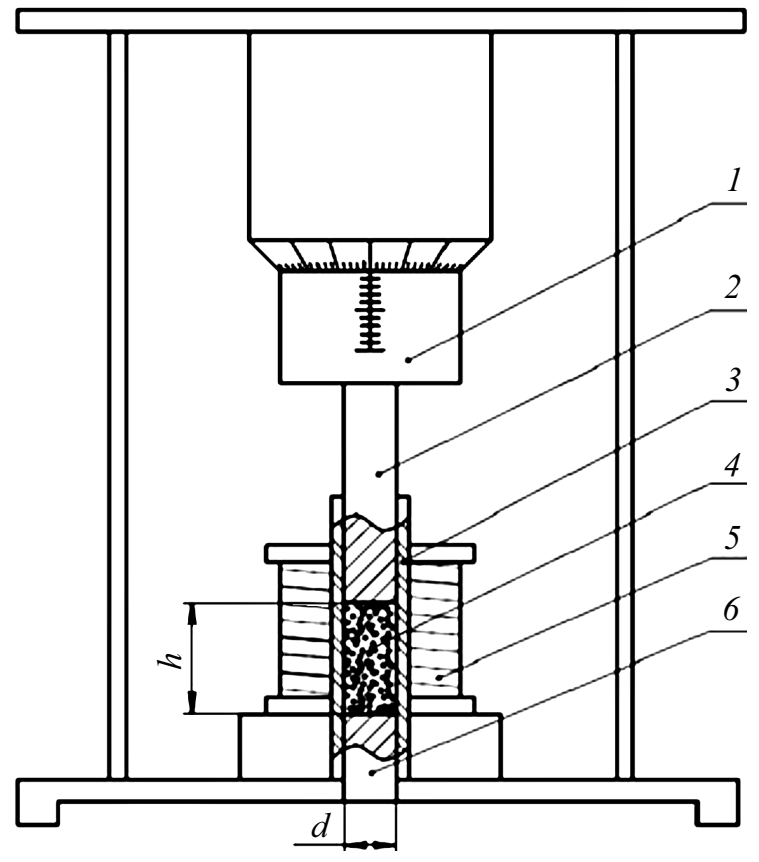

Рис. 2. Контактная система для измерения электрофизических характеристик массивов МУНТ: 1 - микрометрический винт; 2 - подвижный электрод; 3 - кювета; 4 - массив МУНТ; 5 - нагреватель; 6 - неподвижный электрод.

позволяющего изменять температуру кюветы в диапазоне $25-100^{\circ} \mathrm{C}$.

Для исследования свойств массивов МУНТ при различном давлении сжатия использовалась контактная система из оргстекла, закрепленного на металлическом основании, которое служило общим контактом для всех исследуемых образцов. В три цилиндрические кюветы в оргстекле диаметром $1.7 \mathrm{~mm}$ засыпаются МУНТ, которые сверху сжимаются медными стержнями-поршнями с лужеными торцами. Эти стержни выполняли роль пресса и второго электрического контакта. На свободном конце стержней были закреплены круглые пластины, на которые помещался груз различной массы. Измерение высоты образцов массивов МУНТ осуществлялось микрометром с точностью до $10 \mu \mathrm{m}$.

Масса массивов МУНТ измерялась лабораторными весами ВЛТЭ-150 с ценой деления $1 \mathrm{mg}$. Сила тока, протекающего через массив МУНТ, и напряжение на электродах измерялись двумя универсальными вольтметрами B7-21А, включенными в режиме амперметра и вольтметра соответственно.

\section{Результаты исследования электропроводности массивов МУНТ}

Исследованы пять образцов массивов МУНТ: 1 - исходные; 2 - после отжига; 3 - после отжига с обработкой $\mathrm{HCl} ; 4$ - после отжига с обработкой серной 


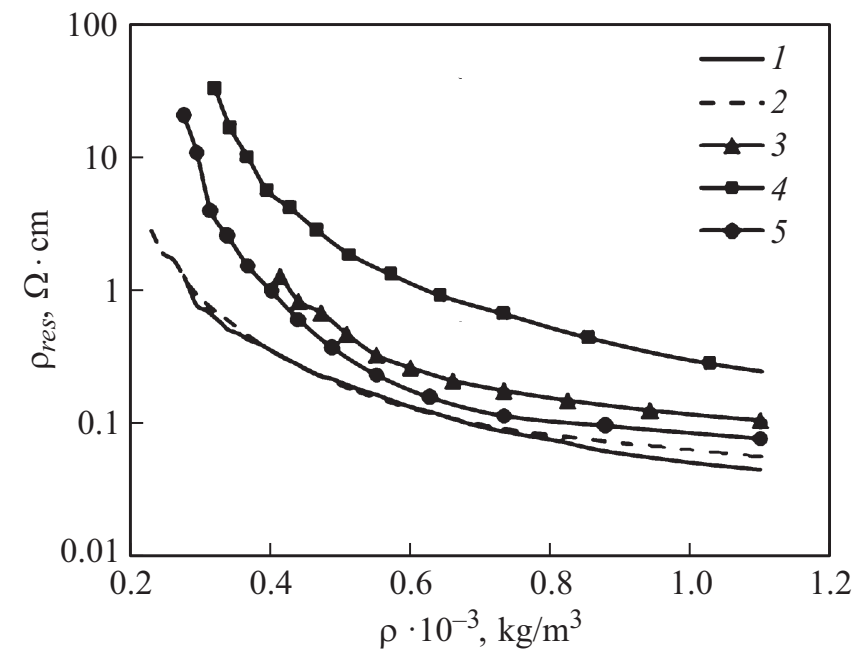

Рис. 3. Зависимости удельного объемного электрического сопротивления $\rho_{\text {res }}$ различных образцов массивов МУНТ от плотности массива $\rho$.

Таблица 1. Значения удельного объемного электрического сопротивления образцов МУНТ при плотности массива $600 \mathrm{~kg} / \mathrm{m}^{3}$

\begin{tabular}{c|c|c|c|c|c}
\hline № образца & 1 & 2 & 3 & 4 & 5 \\
\hline$\rho_{\text {res }}, \Omega \times \mathrm{cm}$ & 0.133 & 0.130 & 0.262 & 1.102 & 0.173
\end{tabular}

и азотной кислотами; 5 - после обработки серной и азотной кислотами.

Измерены зависимости удельного объемного сопротивления $\rho_{\text {res }}$ пяти образцов массивов МУНТ от плотности массива $\rho$. Графики приведены на рис. 3 .

В табл. 1 приведены значения удельного объемного электрического сопротивления исследованных образцов МУНТ при плотности массива $600 \mathrm{~kg} / \mathrm{m}^{3}$. Массивы исходных и отожженных МУНТ имеют близкие значения удельного сопротивления. После обработки соляной кислотой сопротивление МУНТ возрастает в 2 раза. Наибольшее удельное сопротивление имеют МУНТ, отожженные и обработанные кислотами.

Большинство авторов $[6,7,11]$ считают, что проводимость массивов УНТ определяется главным образом не проводимостью самих УНТ, которая, как известно, сравнима с проводимостью хорошо проводящих металлов, а свойствами контактов между УНТ. При исследовании влияния разных способов функционализации на электропроводность массивов МУНТ авторы [6] обнаружили увеличение проводимости при обработке кислотой и отжиге, а также при обработке ультрафиолетовым излучением. Однако в указанной работе не представлено удовлетворительного объяснения наблюдаемым эффектам.

В отличие от результатов работы [6] нами установлено, что простой отжиг МУНТ практически не
Таблица 2. Значения ТКС образцов МУНТ при давлении $65 \mathrm{~kg} / \mathrm{cm}^{2}$

\begin{tabular}{c|c|c|c|c|c}
\hline № образца & 1 & 2 & 3 & 4 & 5 \\
\hline ТКС, $\mathrm{K}^{-1}$ & $-1.9 \cdot 10^{-3}$ & $-0.5 \cdot 10^{-3}$ & $17 \cdot 10^{-3}$ & $8 \cdot 10^{-3}$ & $30 \cdot 10^{-3}$
\end{tabular}

приводит к изменению проводимости во всем исследованном диапазоне плотностей массивов. Обработка кислотами как с отжигом, так и без него приводит к увеличению удельного сопротивления. Особенно сильно это проявляется при малых плотностях, когда связи между МУНТ в массиве заметно меньше. Наибольшее (более чем на порядок величины) увеличение удельного сопротивления массивов МУНТ наблюдается при совместном воздействии отжига и смеси кислот. Это, на наш взгляд, объясняется установленным в [7] снижением способности функционализированных МУНТ к агрегатированию и кластеризации. В результате функционализации плотность электронных связей между отдельными МУНТ в массиве снижается, и электропроводность падает. С увеличением сжатия МУНТ различие проводимости исходных и функционализированных различными способами МУНТ уменьшается.

С увеличением температуры массива исходных МУНТ наблюдается слабое уменьшение электрического сопротивления по закону, близкому к линейному, с относительным температурным коэффициентом сопротивления (ТКС), равным $-1.9 \cdot 10^{-3} \mathrm{~K}^{-1}$. Температурные коэффициенты функционализированных МУНТ приведены в табл. 2.

По величине удельного электрического сопротивления и характеру зависимости от температуры массивы исходных МУНТ и МУНТ, подвергнутых температурному отжигу, относятся к полупроводникам, что согласуется с результатами других авторов [3,5-7]. Функционализированные кислотами МУНТ проявляют металлические свойства.

\section{Результаты исследования шумовых свойств массивов МУНТ}

С целью изучения особенностей прохождения тока через массивы МУНТ проведено измерение и анализ вероятностных характеристик шума, возникающего на подводящих электродах при протекании тока. Измерение шумовых характеристик МУНТ проводилось при комнатной температуре аппаратно-программным комплексом [12], настроенным для измерения шума низкоомных резисторов. Шумовая реализация с линейного выхода селективного нановольтметра в течение $10 \mathrm{~s}$ подвергалась аналого-цифровому преобразованию с частотой дискретизации $1 \mathrm{MHz}$ и сохранялась в память компьютера в виде массива дискретных отсчетов. 


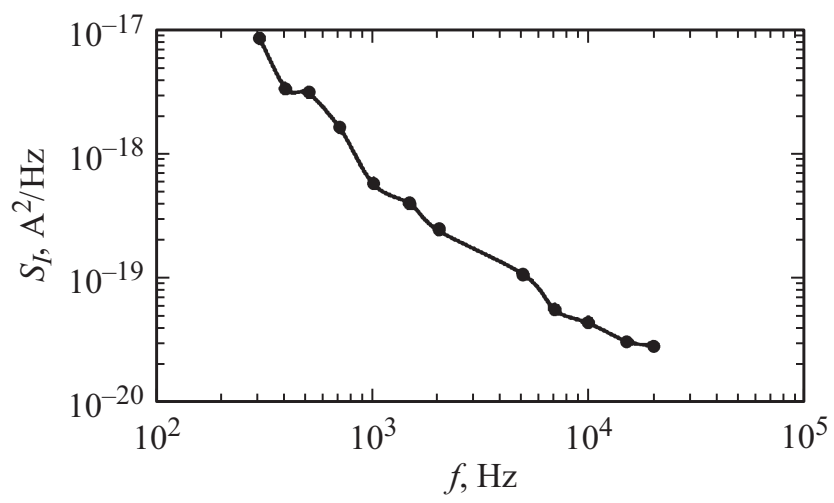

Рис. 4. Спектральная плотность шума тока массива МУНТ, измеренная при токе $20 \mathrm{~mA}$ и давлении $65 \mathrm{~kg} / \mathrm{cm}^{2}$.

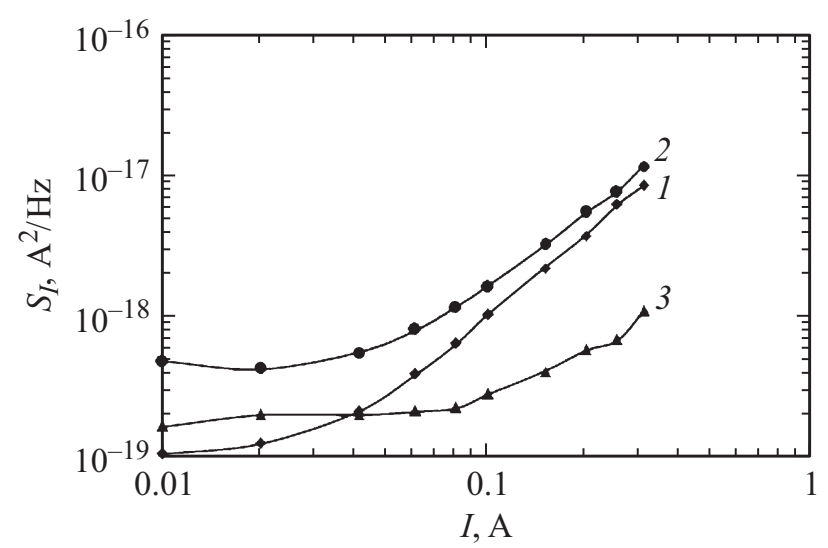

Рис. 5. Токовые зависимости НЧ-шума массивов МУНТ, измеренные на частоте $10 \mathrm{kHz}$ при давлении $65 \mathrm{~kg} / \mathrm{cm}^{2}: 1$ - исходные МУНТ; 2 - МУНТ после отжига; 3 - МУНТ после отжига с обработкой $\mathrm{HCl}$.

В диапазоне низких частот у всех образцов массивов МУНТ зарегистрирован наблюдаемый и другими авторами $[8,9]$ НЧ-шум со спектром $1 / f^{\gamma}$, где показатель степени $\gamma$ близок к единице (рис. 4). В диапазоне частот $10-150 \mathrm{kHz}$ спектральная плотность шумового тока практически не зависит от частоты и соответствует уровню теплового шума резистора сопротивлением $R \approx 0.5 \Omega$, что близко измеренным значениям сопротивления образцов массивов МУНТ.

На рис. 5 представлены зависимости спектральной плотности мощности шума на частоте $10 \mathrm{kHz}$ различных образцов массивов МУНТ при давлении $65 \mathrm{~kg} / \mathrm{cm}^{2}$. При токе $10 \mathrm{~mA}$ шумы массивов МУНТ после отжига примерно в 5 раз больше, чем шумы массивов исходных МУНТ. После обработки соляной кислотой уровень шума заметно снижается, не достигая исходных значений. При этом шум массивов исходных МУНТ и МУНТ после отжига с ростом силы тока вплоть до значений тока $40 \mathrm{~mA}$ изменяются слабо, а затем начинают расти по закону, близкому $I^{2}$. Шум массива МУНТ после отжига и обработки соляной кислотой практически не изменяется до тока $100 \mathrm{~mA}$, а затем растет по степенному закону вида $I^{1.2}$.

Характер шума массивов МУНТ и его вероятностные характеристики в значительной степени зависят от плотности массива. На рис. 6 представлены фрагменты реализаций шума (сигнала на выходе линейного усилителя) массива исходных МУНТ при плотностях $228 \mathrm{~kg} / \mathrm{m}^{3}(a)$ и $913 \mathrm{~kg} / \mathrm{m}^{3}(b)$. Из рисунка видно, что с увеличением плотности массива амплитуда флуктуаций (выбросов) возрастает, а длительность - уменьшается.

На рис. 7 представлены гистограммы распределений выбросов шумового напряжения на выходе линейного усилителя по амплитуде, а на рис. 8 - по длительности при трех значениях плотности массива исходных МУНТ: 228,365 и $913 \mathrm{~kg} / \mathrm{m}^{3}$. На графиках рис. 8 - по оси абсцисс отложены значения длительности $\tau$ выброса шумового напряжения, превышающего уровень $0 \mathrm{~V}$, а по оси ординат - среднее количество выбросов, превышающих уровень $0 \mathrm{~V}$ в течение времени $1 \mathrm{~s}$. При низкой плотности массива исходных МУНТ распределение выбросов шума по амплитуде имеет распределение, близкое к нормальному со смещенным средним (рис. $7, a$ ). При увеличении плотности массива распреде-
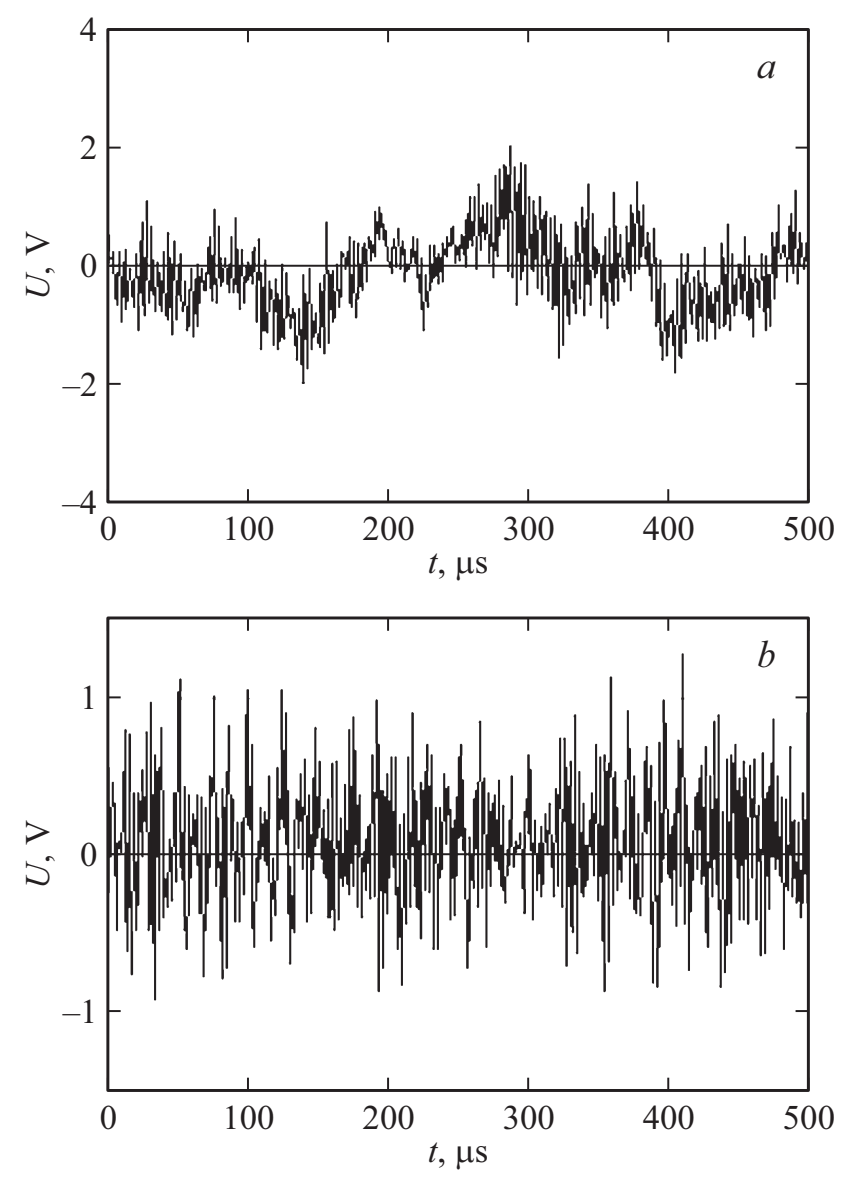

Рис. 6. Фрагменты реализаций шума (сигнала на выходе линейного усилителя) массива исходных МУНТ при плотностях $228 \mathrm{~kg} / \mathrm{m}^{3}$ (a) и $913 \mathrm{~kg} / \mathrm{m}^{3}(b)$. 

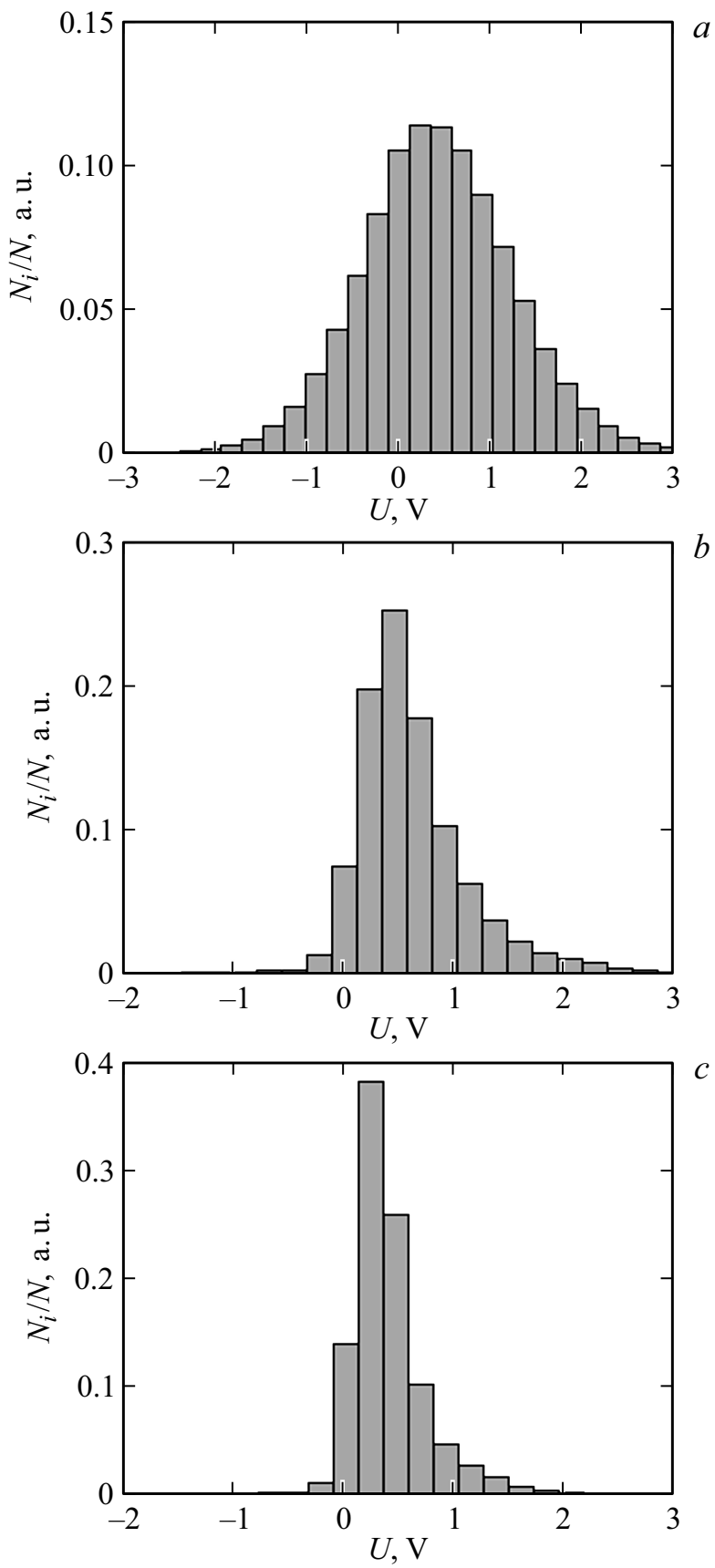

Рис. 7. Гистограммы распределения выбросов шумового тока по амплитуде при плотности тока $45 \mathrm{~mA} / \mathrm{cm}^{2}$ и плотностях массива исходных МУНТ: $a-228, b-365, c-913 \mathrm{~kg} / \mathrm{m}^{3}$.

ление выбросов шума по амплитуде трансформируется в логарифмически-нормальное (рис. 7, $b, c$ ).

При увеличении плотности массива характер распределения выбросов шумового тока по длительности изменяется незначительно, но сильно сокращается размах распределения по длительности. Длительность выбросов определяется временем нахождения электронов в связанном состоянии на ловушках. Параметры распределений шумовых выбросов по амплитуде и длительности приведены в табл. 3 и 4 соответственно.
Средняя амплитуда выбросов изменяется немонотонно, а СКО монотонно спадает с ростом плотности массива. Средняя длительность выбросов слабо нелинейно уменьшается с увеличением плотности массива (с 228 до $913 \mathrm{~kg} / \mathrm{m}^{3}$ ), а СКО длительности выбросов резко уменьшается более чем на порядок, что свидетельствует о сокращении времени нахождения электронов в локализованном состоянии на ловушках.

Распределения выбросов шумового тока по амплитуде и длительности определяются механизмами токопро-
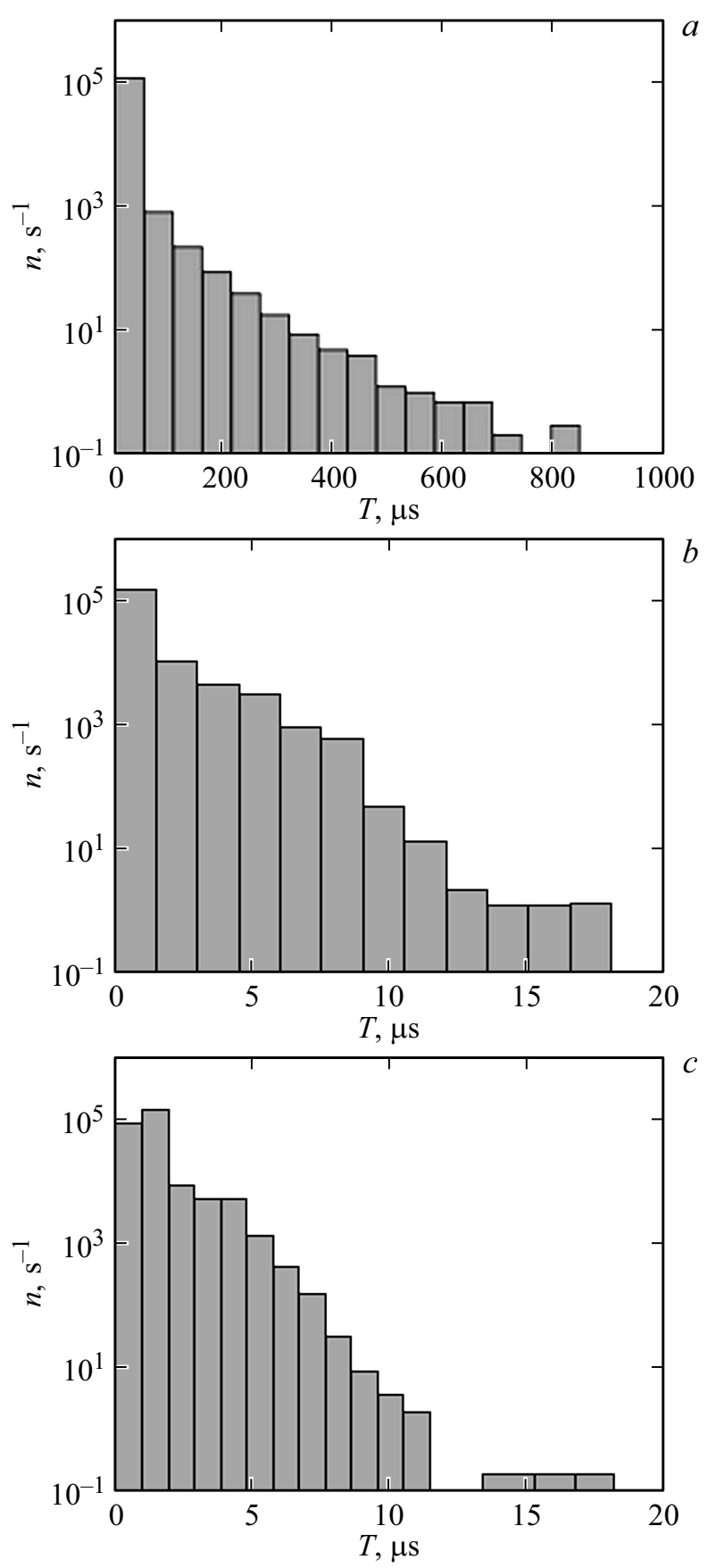

Рис. 8. Гистограммы распределения выбросов шумового тока по длительности при плотности тока $45 \mathrm{~mA} / \mathrm{cm}^{2}$ и плотностях массива исходных МУНТ: $a-228, b-365, c-913 \mathrm{~kg} / \mathrm{m}^{3}$. 
Таблица 3. Характеристики распределения выбросов шумового тока по амплитуде

\begin{tabular}{l|c|c|c}
\hline \multirow{2}{*}{} & \multicolumn{3}{|c}{ Плотность массива МУНТ } \\
\cline { 2 - 4 } & $228 \mathrm{~kg} / \mathrm{m}^{3}$ & $365 \mathrm{~kg} / \mathrm{m}^{3}$ & $913 \mathrm{~kg} / \mathrm{m}^{3}$ \\
\hline $\begin{array}{l}\text { Среднее значение } \\
\text { амплитуды выброса, V }\end{array}$ & 0.25 & 0.44 & 0.21 \\
\hline $\begin{array}{l}\text { Среднеквадратическое } \\
\text { отклонение (СКО), V }\end{array}$ & 0.88 & 0.70 & 0.43
\end{tabular}

Таблица 4. Характеристики распределения выбросов шумового тока по длительности

\begin{tabular}{l|c|c|c}
\hline & \multicolumn{3}{|c}{ Плотность массива МУНТ } \\
\cline { 2 - 4 } & $228 \mathrm{~kg} / \mathrm{m}^{3}$ & $365 \mathrm{~kg} / \mathrm{m}^{3}$ & $913 \mathrm{~kg} / \mathrm{m}^{3}$ \\
\hline $\begin{array}{l}\text { Средняя длительность } \\
\text { выброса шума, } \mu \mathrm{s}\end{array}$ & 2.2 & 1.3 & 1.2 \\
\hline $\mathrm{CКО,} \mu \mathrm{s}$ & 13.3 & 1.0 & 0.9
\end{tabular}

хождения, которые в массивах МУНТ имеют перколяционный характер $[11,13,14]$. Полученные результаты могут быть полезны при разработке модели НЧ-шума в массивах МУНТ.

\section{Заключение}

1. По величине и характеру температурной зависимости удельного электрического сопротивления массивы исходных МУНТ и МУНТ, подвергнутых отжигу, относятся к полупроводникам, что согласуется с результатами других авторов [3,5-7]. Массивы из отожженных и функционализированных кислотами МУНТ проявляют металлические свойства.

2. Функционализация с использованием кислот приводит к существенному увеличению удельного сопротивления образцов массивов МУНТ, что объясняется снижением способности функционализированных МУНТ к агрегатированию и уменьшением электронных связей между отдельными МУНТ в массиве. Наибольшее увеличение сопротивления массивов МУНТ наблюдается при последовательном воздействии отжига, обработки в соляной, и, затем, в смеси азотной и серной кислот.

3.У всех образцов массивов МУНТ в диапазоне от $200 \mathrm{~Hz}$ до $20 \mathrm{kHz}$ наблюдается НЧ-шум вида $1 / f^{\gamma}$. Простой отжиг приводит к увеличению уровня шума в несколько раз, а отжиг с обработкой кислотами к снижению уровня шума и изменению показателя степени в токовой зависимости.

4. При небольшой плотности массивов МУНТ распределение выбросов шумового тока по амплитуде близко к нормальному, а с увеличением плотности становится логарифмически-нормальным. При этом размах распределения выбросов по длительности существенно уменьшается. Такой характер изменения формы распределения выбросов шума по амплитуде и длительности свидетельствует о перколяционном механизме токопрохождения в массивах МУНТ.

\section{Финансирование работы}

Работа выполнена в рамках государственного задания.

\section{Конфликт интересов}

Авторы заявляют, что у них нет конфликта интересов.

\section{Список литературы}

[1] Сорокин П.Б., Чернозатонский Л.А. // УФН. 2013. Т. 183. № 2. C. 113-132. DOI: 10.3367/UFNr.0183.201302a.0113

[2] Нищенко М.М., Михайлова Г.Ю., Архипов Е.И. идр. // Nanosystems, Nanomaterials, Nanotechnologies. 2009. Vol. 7. N 3. P. 717-726.

[3] Marinho B., Ghislandi M., Tkalya E., Koning Cor E., de With G. // Powder Technol. 2012. Vol. 221. P. 351-358. DOI: 10.1016/j.powtec.2012.01.024

[4] Климов Е.С., Бузаева М.В., Давыдова О.А., Макарова И.А. идр. // Башкирский химический журн. 2014. Т. 21. № 3. C. 109-113.

[5] Singjai P., Changsarn S., Thongtem S. // Mater. Sci. Eng. 2007. A 443. P. 42-46. DOI: 10.1016/j.msea.2006.06.042

[6] Cher Hon Lau, Raoul Cervini, Stephen R. Clarke et al. // J. Nanopart Res. 2008. Vol. 10. P. 77-88. DOI: 10.1007/s11051008-9376-1

[7] Захарычев Е.А., Рябов С.А., Семчиков Ю.Д. идр. // Вестник Нижегородского ун-та им. Н.И. Лобачевского. 2013. № 1 (1). C. 100-104.

[8] Kogan Sh. Electronic Noise and Fluctuations in Solids. Cambridge University Press, 2008. 354 p.

[9] Barone C., Pagano S., Neitzert H.C. // J. Appl. Phys. 2011. Vol. 110. P. 113716. DOI: $10.1063 / 1.3666052$

[10] Климов Е.С., Бузаева М.В., Давыдова О.А., Макарова И.А. идр. // ЖПХ. 2014. Т. 87. № 8. С. 1128-1132.

[11] Заднепровский Б.И., Клюев И.Ю., Турков В.Е. // Письма в ЖТФ. 2016. Т. 42. Вып. 16. С. 87-94.

[12] Сергеев В.А., Фролов И.В., Широков А.А. // Промышленные АСУ и контроллеры. 2012. № 11. С. 46-48.

[13] Раммал Р. Фракталы в физике. Труды 6-го Международного симпозиума по фракталам в физике. Триест, Италия, 1985. / Пер. изд. М.: Мир, 1988. 672 с.

[14] Rammal R., Trembley A.-M.S. // Phys. Rev. Lett. 1987. Vol. 58. N 4. P. 415-418. DOI: org/10.1103/PhysRevLett.58.415 